\title{
CARACTERIZAÇÃO DE BIOPOLÍMEROS PRODUZIDOS POR Beijerinckia sp. 7070 EM DIFERENTES TEMPOS DE CULTIVO'
}

\author{
Caroline Dellinghausen BORGES ${ }^{2}$, Ângela Nunes MOREIRA ${ }^{2,3}$, Angelita da Silveira MOREIRA²,
}

Francisco A. B. DEL PINO ${ }^{4}$, Claire Tondo VENDRUSCOLO ${ }^{2,3, *}$

\section{RESUMO}

Biopolímeros são polissacarídeos microbianos. O biopolímero produzido por Beijerinckia sp. 7070 possui comportamento pseudoplástico e apresenta alta viscosidade em baixas velocidades de deformação, conferindo ao polímero excelentes características de suspensão. $O$ objetivo desse trabalho foi caracterizar o biopolímero produzido por Beijerinckia sp. 7070 em diferentes tempos de cultivo, quanto à produção total, produção de polímeros de fibra longa e curta, produtividade, viscosidade e composição química. Os polímeros produzidos em meio YM líquido foram recuperados em diferentes tempos de cultivo, secos e pesados para determinação da produção e produtividade. O tipo de fibra produzido durante o cultivo foi avaliado microscopicamente. Viscosidades aparentes de solução aquosa $1 \%$ foram determinadas a $6,12,30$ e $60 \mathrm{rpm}$, a $25^{\circ} \mathrm{C}$, em um viscosímetro Brookfield. A composição do biopolímero foi determinada por cromatografia em camada delgada comparativa. As maiores produções totais encontradas foram em 30 e $72 \mathrm{~h}$, a maior produtividade em $48 \mathrm{~h}$ e a maior viscosidade em $72 \mathrm{~h}$. Os polímeros de fibra longa apresentaram uma tendência de tornarem-se mais longos com o tempo. A viscosidade do polímero de fibra longa foi maior que a do de fibra curta. Todos os biopolímeros apresentaram os mesmos componentes (glucose, galactose, fucose e ácido glucurônico) mas em concentrações diferentes.

Palavras-chave: biopolímero; cultivo; viscosidade; Beijerinckia sp.

\section{SUMMARY}

CHARACTERIZATION OF BIOPOLYMERS PRODUCED BY Beijerinckia sp 7070 AT DIFFERENT CULTURE TIMES. Biopolymers are microbial polysaccharides. The biopolymer produced by Beijerinckia sp 7070 has pseudoplastic behaviour and shows high viscosity at low deformation rates, giving to polymer excellent suspension characteristics. The objective of this work was to characterize the biopolymer produced at different culture times by Beijerinckia sp 7070 in relation to total production, production of short and long fiber polymers, productivity, viscosity and chemical composition. The polymers produced in liquid YM medium were recovered at different culture times, dried and weighted for determination of the production and productivity. Fiber type produced during the culture times was evaluated microscopically. Apparent viscosities of the $1 \%(\mathrm{w} / \mathrm{v})$ aqueous solutions were determined at $6,12,30$ and $60 \mathrm{rpm}$, at $25^{\circ} \mathrm{C}$, in a Brookfield viscosimeter. Biopolymer composition was determined by comparative thin layer chromatography. The highest total biopolymer productions was found at 30 and $72 \mathrm{~h}$, the highest productivity was at $48 \mathrm{~h}$ and the highest viscosity was at $72 \mathrm{~h}$. The long fiber polymer showed a tendency of becoming longer with time. The viscosity of long fiber polymer was higher than the short fiber one. All polymers showed the same components (glucose, galactose, fucose and glucuronic acid) but at different concentrations.

Keywords: biopolymer; culture; viscosity; Beijerinckia sp.

\section{1 - INTRODUÇÃO}

Atualmente há considerável interesse em polissacarídeos obtidos pela ação de microrganismos. Estes polissacarídeos, conhecidos como biopolímeros, são obtidos por processos fermentativos. Possuem capacidade de formar soluções viscosas e géis em meio aquoso, mesmo quando aplicados em baixas concentrações. O monoesterato glicerol e a carboximetilcelulose são emulsificantes amplamente utilizados na indústria de alimentos. Embora muito efetivos nas suas funções, estes componentes estão perdendo gradualmente seu campo devido a maior conscientização dos consumidores em reduzir o uso de aditivos artificiais ou quimicamente sintetizados em alimentos. A produção de emulsificantes através de cultivo micro-

\footnotetext{
1. Recebido para publicação em 25/05/2002. Aceito para publicação em 19/05/2004 (000853).

2. Centro de Biotecnologia - Laboratório de Biopolímeros - Universidade Federal de Pelotas. Caixa Postal 354, CEP: 96010-900, Pelotas, RS. Telefone: (053) 275-7350. E-mail: claire@ufpel.tche.br

3. Programa de Pós-graduação em Ciência e Tecnologia de Alimentos UFPel.

4. Departamento de Bioquímica - Instituto de Química e Geociência UFPel.

* A quem a correspondência deve ser enviada.
}

biano, além de solucionar esse problema, pois produz polímero de natureza biodegradável, é eficiente a uma ampla margem de temperatura, $\mathrm{pH}$ e força iônica, e ainda possui capacidade de síntese em condições desfavoráveis, como baixas temperaturas e pressão [14]. Além disso, os biopolímeros apresentam vantagens também em relação aos polissacarídeos de origem vegetal e animal, tais como: reprodutibilidade e estabilidade das propriedades físico-químicas e custo e suprimento estáveis [10]. Devido as suas propriedades físico-químicas os biopolímeros podem ser utilizados amplamente na indústria como emulsificantes, gelificantes e estabilizantes [12]. Os polissacarídeos microbianos atualmente utilizados em produção industrial são a dextrana, que é uma glucana neutra e a xantana, um heteropolissacarídeo poliânico [5].

A produção de polissacarídeos extracelulares é muito comum em muitos gêneros de bactérias. Esses exopolissacarídeos podem formar uma cápsula ao redor da célula ou podem ser excretados para o meio ambiente como um muco [3]. A Beijerinckia sp 7070 é uma bactéria fixadora de nitrogênio. Espécies de bactérias fixadoras de nitrogênio são geralmente produtoras de exopolissacarídeos [6].

Os exopolissacarídeos ácidos produzidos pela maioria das bactérias fitopatogênicas são altamente aniôni- 
cos. Os homopolímeros incluem glucanas, levanas e alginatos. Os heteropolímeros são polímeros ácidos compostos de arranjamentos lineares de unidades repetitivas de açúcares neutros, ácido glucurônico e radicais de acetato, piruvato, hidroxibutirato e succinato [17].

A composição do biopolímero influencia o seu comportamento reológico. A gelatinização da xantana é amplamente afetada especialmente pela relação D-manose:D-galactose [16].

Alguns componentes tais como D-glucose, D-manose, D-galactose e D-ácido glucurônico ocorrem muito freqüentemente, outros como L-ramnose ou L-fucose são menos comuns e o D-ácido manurônico e o L-ácido glucurônico são raros [15].

Os biopolímeros que despertam interesse industrial devem apresentar característica de elevada viscosidade em ampla faixa de $\mathrm{pH}$ e temperatura e devem apresentar composição química compatível com o metabolismo humano. Estudos estão sendo desenvolvidos para otimizar o processo de produção visando à obtenção de biopolímeros com potencial aplicação industrial e alta produtividade. No entanto, para a produção industrial, é de extrema importância o desenvolvimento de processos econômicos que visam a redução de meios de cultura e do tempo de cultivo [8]. Em estudos realizados por VENDRUSCOLO [19] foi demonstrada a viabilidade industrial do biopolímero produzido por Beijerinckia sp 7070 através das respostas de rendimento, comportamento reológico, estabilidade ao $\mathrm{pH}$, temperatura e tempo de produção. Além disso, PADILHA, DELLAGOSTIN \& VENDRUSCOLO [11] observou em um estudo onde analisou somente dois tempos (24 e 36 horas), que a produção, composição química e a viscosidade variou entre os tempos. Portanto é importante estudar o(s) melhor(es) tempo(s) de cultivo para obtenção de uma maior quantidade e melhor qualidade do biopolímero.

O presente trabalho teve como objetivo caracterizar o biopolímero produzido pela bactéria Beijerinckia sp 7070, em diferentes tempos de cultivo, quanto à produção total, produção de polímeros de fibra longa e curta, produtividade, viscosidade e composição química.

\section{2 - MATERIAIS E MÉTODOS}

\section{1 - Microrganismo}

Foi utilizada a bactéria Beijerinckia sp 7070, que foi isolada do solo de plantação de cana-de-açúcar na região de Ribeirão Preto-SP, identificada e caracterizada como produtora de biopolímero por VENDRUSCOLO [19].

\section{2 - Meios e condições de incubação}

Durante o desenvolvimento do trabalho a cultura foi mantida através de liofilização em ampolas. Nesse processo, a suspensão bacteriana com $1 \times 10^{10}$ UFC de Beijerinckia sp 7070 por mL acrescida de crioprotetor foi conservada através da dessecação a pressões sub-atmosféricas. Além disso, repiques a cada trinta dias em YM agar foram feitos [5]. As placas cultivadas com
Beijerinckia sp 7070 foram incubadas a $24^{\circ} \mathrm{C}$, por 24 horas e estocadas a $4^{\circ} \mathrm{C}$.

Para a produção de biopolímero utilizou-se o meio YM líquido contendo (g. $\mathrm{L}^{-1}$ ): (1) $\mathrm{K}_{2} \mathrm{HPO}_{4} 2,0, \mathrm{MgSO}_{4} 7 \mathrm{H}_{2} \mathrm{O}$ $2,7, \mathrm{KH}_{2} \mathrm{PO}_{4}$ 13,62; (2) extrato de levedura 0,2, triptose 2,0; (3) sacarose 50,0 [20]. O pH da solução (1) foi ajustado a 6,8 e as três soluções foram autoclavadas separadamente a $121^{\circ} \mathrm{C}$ por 15 minutos. Utilizou-se metodologia de VENDRUSCOLO [19] modificada por PADILHA, DELLAGOSTIN \& VENDRUSCOLO [11]. O inóculo utilizado na produção foi de $1 \mathrm{~mL}$ de suspensão bacteriana com $1 \times 10^{10} \mathrm{UFC} / \mathrm{mL}$ preparado a partir de colônias de 24 horas de crescimento. O inóculo foi acrescentado a $100 \mathrm{~mL}$ de meio de produção, em Erlenmeyer de $250 \mathrm{~mL}$. A produção de biopolímero foi realizada por fermentação aeróbia em batelada, em incubador agitador New Brunswick Scientific, modelo Innova 4230. As condições de incubação foram: $24^{\circ} \mathrm{C}, 180 \mathrm{rpm}$ e os tempos utilizados foram: $16,18,20,24,28,30,32,34,36$, 48,72 e 96 horas.

\section{3 - Recuperação dos polímeros}

Para remoção das células, os meios cultivados de cada tempo foram centrifugados a $16000 \mathrm{~g}$ por 20 minutos à temperatura de $4^{\circ}$ a $14^{\circ} \mathrm{C}$. Ao sobrenadante adicionouse etanol 95\% na proporção de 1:4 (v/v) para recuperação dos biopolímeros. Os polímeros apresentaram fibras longas e curtas. As fibras longas foram separadas das fibras curtas através de peneira, com 42 orifícios $/ \mathrm{cm}^{2}$ sendo as fibras curtas recolhidas após decantação. Os biopolímeros foram secos em estufa a $56^{\circ} \mathrm{C}$ até atingir massa constante e após foram pesados e triturados.

\section{4 - Produção de biopolímero}

A produção total dos biopolímeros e a produção dos polímeros de fibra longa e curta (g/L) obtidos nos diferentes tempos de cultivo foram avaliadas pela massa do produto seco por volume de meio. Foi realizada ainda análise microscópica dos polímeros em microscópio óptico OLYMPUS modelo BX50 de contraste interferencial de fases. O sistema de microfotografia utilizado foi composto por câmera digital SONY modelo DXC-107A e monitor de vídeo SONY HR Triniton. Foi utilizada placa de captura de imagem ATI Technologies Inc modelo ALLIN-WONDER ${ }^{\mathrm{TM}}$ PRO adaptada a um computador.

Um aumento de 40 vezes foi usado para observação visual dos polímeros de fibra longa e curta nos diferentes tempos.

\section{5 - Produtividade}

A produtividade (g/L.h) foi avaliada pela massa do produto seco por volume de meio por tempo de cultivo.

\section{6 - Viscosidade}

A determinação da viscosidade da solução aquosa dos biopolímeros a $1 \%(\mathrm{~m} / \mathrm{v})$ foi realizada em viscosímetro rotacional Brookfield modelo LV, com spindle 3, a $25^{\circ} \mathrm{C}$, nas seguintes velocidades de deformação: 6 , 12,30 e 60 rpm. 


\section{7 - Análise estatística}

Todas as amostras, em triplicata, foram analisadas estatisticamente pelo método de Fischer.

\section{8 - Análise cromatográfica}

Para preparar as amostras para cromatografia, foi realizada hidrólise dos biopolímeros em $\mathrm{HCl} 1 \mathrm{~N}$ $(3 \% \mathrm{~m} / \mathrm{v})$ a $80^{\circ} \mathrm{C}$ por 16 horas em banho-maria com temperatura controlada. A composição dos biopolímeros foi determinada através de cromatografia em camada delgada comparativa (CCDC) em cromatofolhas de alumínio de sílica gel $60 \mathrm{~F}_{254}$, Merck. O eluente empregado foi clorofórmio:metanol:ácido acético:água, na proporção de 40:40:10: 10 (v/v/v/v). Para revelação utilizou-se o reagente anizaldeído sulfúrico. Os padrões utilizados foram: fucose, ácido glucurônico, galactose, glucose e ácido galacturônico.

\section{3 - RESULTADOS E DISCUSSÃO}

\section{1 - Produção de biopolímero}

A produção total de biopolímeros nos diferentes tempos apresentada na Figura 1 mostrou que a maior produção ocorreu em 30 e 72 horas. Os períodos de aumento se devem, provavelmente a maior presença de enzimas polimerizantes e os de declínio, de enzimas hidrolíticas.

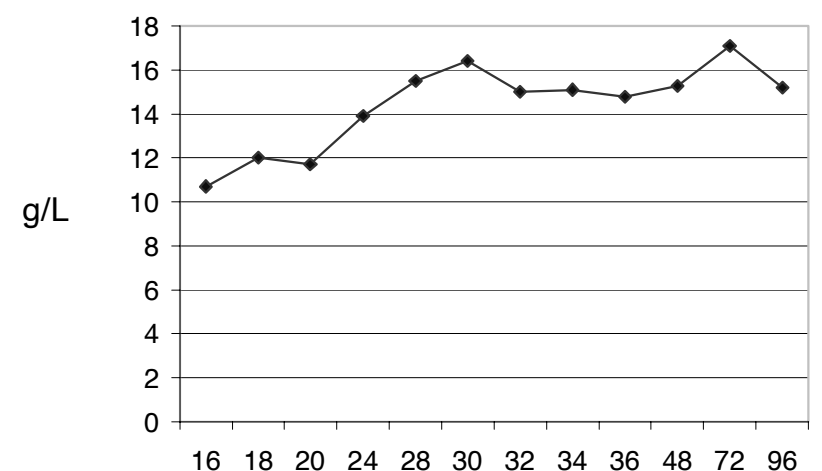

Tempo (h)

FIGURA 1. Produção total $(\mathrm{g} / \mathrm{L})$ de biopolímero em $\mathrm{g} / \mathrm{L}$ por Beijerinckia sp 7070 em diferentes tempos de cultivo.

VENDRUSCOLO [19] obteve em 72 horas de cultivo da mesma bactéria, uma produção total de $10,60 \mathrm{~g} / \mathrm{L}$ nas mesmas condições, porém utilizando além do meio de produção, o meio de crescimento de células. Já neste estudo foi obtido, sem a utilização do meio de crescimento de células, $17,1 \mathrm{~g} / \mathrm{L}$ para o mesmo tempo de cultivo.

Com relação à produção de polímeros de fibras longas e curtas, observamos na Figura 2, que com o passar do tempo aumentou a produção dos de fibra longa e, a partir de 30h, diminuiu a dos de fibra curta. Isso se deve, provavelmente, à ação de enzimas que foram polimerizando esses fragmentos. Observou-se também que em 30 horas ocorreu um equilíbrio entre a quantidade de fibras longas e curtas produzidas (não apresentou diferença estatística).

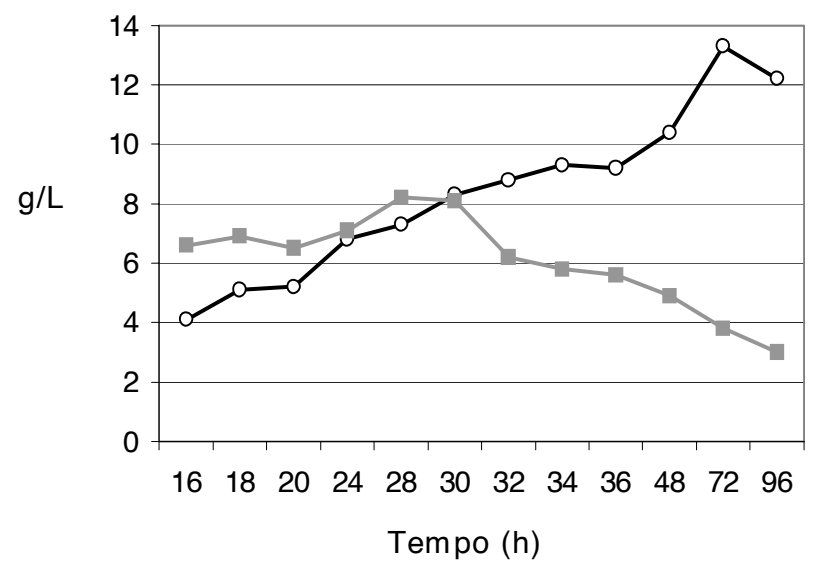

\section{- - fibra longa - - fibra curta}

FIGURA 2. Produção (g/L) de polímeros de fibras longas e curtas por Beijerinckia sp 7070 em diferentes tempos de cultivo.

A Figura 3 apresenta micrografias de polarização (aumento de 40 vezes) dos biopolímeros de fibra longa em 30 horas (A) e em 72 horas (B) e de fibra curta em 72 horas (C). A análise microscópica das fibras mostrou a tendência das fibras longas tornarem-se ainda mais longas com o passar do tempo. As fibras curtas não apresentaram diferença.

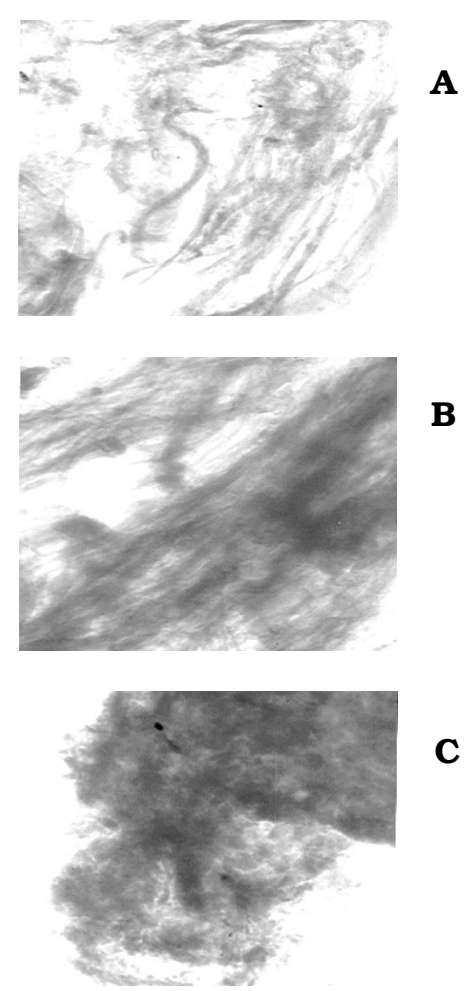

FIGURA 3. Micrografias de polarização (40X) dos biopolímeros de fibra longa em 30 horas (A) e em 72 horas (B) e de fibra curta em 72 horas (C). 


\section{2 - Produtividade}

Como podemos observar na Figura 4, a produtividade dos polímeros de fibra longa permaneceu praticamente constante até 48 horas e, a partir daí observou-se um declínio devido ao maior intervalo de tempo entre os cultivos. Já a produtividade dos de fibra curta decresceu com o passar do tempo, pois estas foram sendo polimerizadas por enzimas específicas.

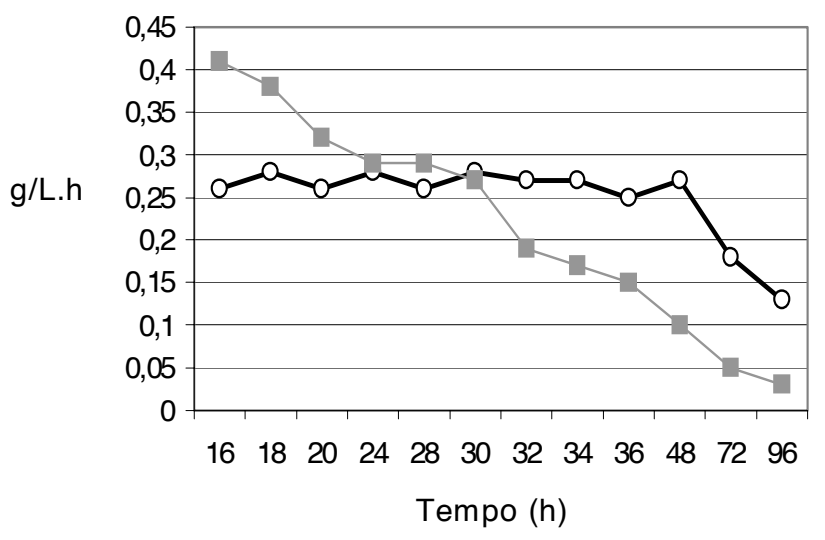

$-0-$ produtividade longas - - produtividade curtas

FIGURA 4. Produtividade (g/L.h) dos biopolímeros de fibra longa e curta em diferentes tempos de cultivo.

Os resultados demonstraram que em 30 e 72 horas ocorreu a maior produção, mas a maior produtividade foi obtida em 48 horas de cultivo.

\section{3 - Viscosidade}

A Tabela 1 apresenta os resultados da análise de viscosidade das soluções aquosas de biopolímeros a $1 \%$ obtidos em diferentes tempos de cultivo medidas a $25^{\circ} \mathrm{C}$, nas velocidades de deformação de $6,12,30$ e 60 rpm e a Figura 5 somente em 30rpm. A maior viscosidade encontrada foi a do biopolímero de fibra longa após 72 horas de cultivo.

Como podemos observar na Figura 5, em geral, os polímeros de fibra longa apresentaram maior viscosidade, e a viscosidade dos de fibra curta permaneceu praticamente estável ao longo do tempo. Até 24 horas de cultivo, as viscosidades dos polímeros de fibra longa e curta permaneceram similares e a partir daí, a viscosidade dos de fibra longa foi aumentando progressivamente apresentando somente um decréscimo em 36 horas. Em 30 horas de cultivo, que foi o tempo em que houve um equilíbrio na quantidade de polímeros de fibras longas e curtas, a viscosidade destes foi igual. PADILHA, DELLAGOSTIN \& VENDRUSCOLO [11] encontrou em 24 e 36 horas de produção maior viscosidade em polímeros de fibra curta do que de fibra longa. Neste trabalho, nos mesmos períodos as viscosidades dos polímeros de fibra longa e curta foram semelhantes.

Entre 18 e 72 horas a produtividade decaiu 35,8\% e neste mesmo período a viscosidade aumentou $97,5 \%$, o que é mais importante.
TABELA 1. Viscosidade aparente de soluções aquosas a $1 \%(\mathrm{~m} / \mathrm{v})$ de biopolímeros obtidos em diferentes tempos de cultivo, medida a $25^{\circ} \mathrm{C}$, em $6,12,30$ e 60rpm.

\begin{tabular}{|c|c|c|c|c|c|}
\hline \multirow{2}{*}{$\begin{array}{l}\text { Tempo } \\
\text { (horas) }\end{array}$} & \multirow{2}{*}{ Tipo de fibra } & \multicolumn{4}{|c|}{ Viscosidade aparente (mPa.s) } \\
\hline & & 6rpm & $12 \mathrm{rpm}$ & 30rpm & $60 \mathrm{rpm}$ \\
\hline \multirow[t]{2}{*}{16} & $\mathrm{FL}^{*}$ & 75 & 75 & 75 & 65 \\
\hline & $\mathrm{FC}^{\star *}$ & 25 & 25 & 30 & 30 \\
\hline \multirow[t]{2}{*}{18} & $\mathrm{FL}$ & 25 & 37,5 & 40 & 37,5 \\
\hline & $\mathrm{FC}$ & 25 & 37,5 & 35 & 35 \\
\hline \multirow[t]{2}{*}{20} & $\mathrm{FL}$ & 50 & 37,5 & 40 & 37,5 \\
\hline & $\mathrm{FC}$ & 50 & 50 & 60 & 55 \\
\hline \multirow[t]{2}{*}{24} & $\mathrm{FL}$ & 50 & 62,5 & 60 & 55 \\
\hline & FC & 25 & 37,5 & 40 & 37,5 \\
\hline \multirow[t]{2}{*}{28} & $\mathrm{FL}$ & 75 & 87,5 & 85 & 75 \\
\hline & FC & 25 & 25 & 20 & 20 \\
\hline \multirow[t]{2}{*}{30} & $\mathrm{FL}$ & 75 & 87,5 & 90 & 82,5 \\
\hline & $\mathrm{FC}$ & 75 & 75 & 90 & 65 \\
\hline \multirow[t]{2}{*}{32} & $\mathrm{FL}$ & 150 & 150 & 135 & 115 \\
\hline & FC & 75 & 75 & 85 & 65 \\
\hline \multirow[t]{2}{*}{34} & $\mathrm{FL}$ & 150 & 150 & 140 & 120 \\
\hline & $\mathrm{FC}$ & 75 & 75 & 75 & 65 \\
\hline \multirow[t]{2}{*}{36} & $\mathrm{FL}$ & 100 & 100 & 100 & 90 \\
\hline & $\mathrm{FC}$ & 75 & 62,5 & 75 & 60 \\
\hline \multirow[t]{2}{*}{48} & $\mathrm{FL}$ & 325 & 312,5 & 250 & 200 \\
\hline & $\mathrm{FC}$ & 75 & 62,5 & 65 & 60 \\
\hline \multirow[t]{2}{*}{72} & $\mathrm{FL}$ & 600 & 525 & 390 & 287,5 \\
\hline & $\mathrm{FC}$ & 65 & 65 & 70 & 65 \\
\hline \multirow[t]{2}{*}{96} & $\mathrm{FL}$ & 425 & 387,5 & 305 & 235 \\
\hline & FC & 60 & 60 & 65 & 60 \\
\hline
\end{tabular}

*FL: polímero de fibra longa
**FC: polímero de fibra curta

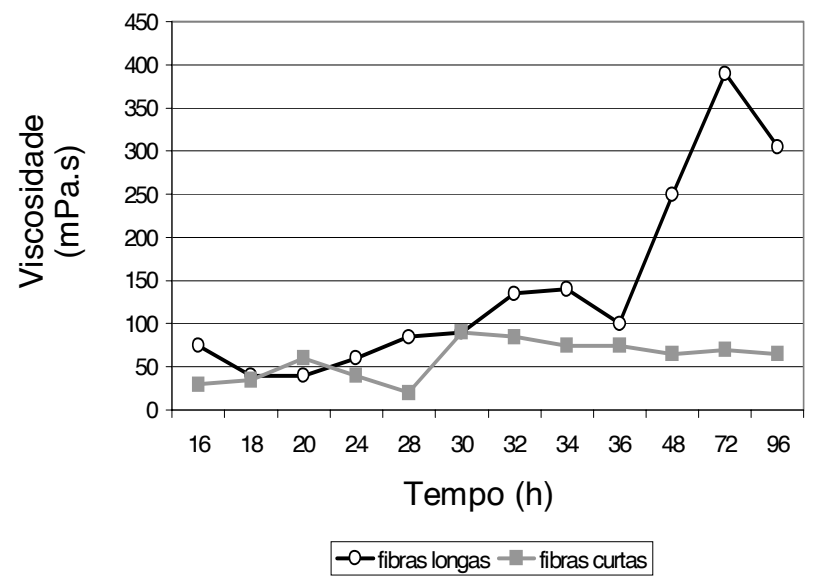

FIGURA 5. Viscosidade aparente de soluções aquosas a $1 \%$ $(\mathrm{m} / \mathrm{v})$ de biopolímeros obtidos em diferentes tempos de cultivo, medida a $25^{\circ} \mathrm{C}, 30 \mathrm{rpm}$.

A viscosidade aparente de soluções aquosas de biopolímeros a 1\%, medidas a 30rpm obtidas após 72 horas de cultivo por VENDRUSCOLO [19] foi de 510mPa.s, enquanto a encontrada nesse estudo do polímero de fibra longa no mesmo período foi de $390 \mathrm{mPa}$.s. No primeiro foi utilizado meio de crescimento de células e no segundo não. 
Em estudos anteriores, foi observado que a viscosidade de soluções aquosas do polissacarídeo produzido por bactérias do gênero Beijerinckia foi maior que a de soluções similares de xantana e a viscosidade foi estável a uma ampla faixa de temperaturas bem como à variação de $\mathrm{pH}$ de 3 a 12 [20].

Os biopolímeros de 16, 18, 20, 24, 28, 30, 32, 34 e 36 horas apresentaram comportamento newtoniano e os de 48, 72 e 96 horas, comportamento pseudoplástico. Os obtidos após 72 e 96 horas por VENDRUSCOLO [19] também apresentaram comportamento pseudoplástico. Soluções aquosas de outros biopolímeros, como a xantana, também são altamente pseudoplásticas [16].

Em um estudo realizado por BUENO \& GARCIACRUZ [1] com a bactéria do gênero Pseudomonas, foi verificada a influência do tempo de cultivo em 24,48 e 72 horas, utilizando-se dois caldos de fermentação diferentes. Em um caldo, a fonte de carbono utilizada foi a glicose e no outro, a sacarose na concentração de $2,0 \%$. Os biopolímeros apresentaram comportamento pseudoplástico e a maior viscosidade aparente obtida foi também em 72 horas de cultivo. O meio contendo sacarose produziu fluidos mais viscosos em 24 e 48 horas e o contendo glicose produziu fluidos mais viscosos somente após 72 horas de cultivo.

Biopolimeros de alta massa molar geralmente apresentam uma série de propriedades úteis incluindo alta viscosidade, e outras de particular interesse para indústria de alimentos devido a suas propriedades de emulsão estabilizante [14]. Alginatos bacterianos normalmente produzem soluções altamente viscosas, em que a viscosidade é dependente da massa molar dos polissacarídeos [16].

No estudo de SHEPHERD et al. [14] nove organismos testados produziram emulsificantes extracelulares tão bons quanto os controles positivos goma arábica e carboximetilcelulose. Entre estes está o biopolímero produzido pela Beijerinckia indica ss. lacticogenes. Este é conhecido como "indicam" e é um polissacarídeo com propriedades lipofílicas [18]. O biopolímero "indicam" deve sua propriedade lipofílica à combinação de aspectos estruturais que incluem uma cadeia linear altamente acetilada (15-20\%) e ao alto conteúdo de desoxi ramnose.

Uma série de texturas de gel pode ser produzida através do controle do nível de acetilação do polímero [7]. Para os polissacarídeos da família das gelanas, a viscosidade intrínseca como uma função da força iônica depende da sua estrutura e da presença ou ausência de grupos acetil. A energia do gel depende dos cátions presentes. DONER \& DOUDS [4] demonstraram a importância da forma dos sais deste polissacarídeo nas suas propriedades de gelatinização e esta seria claramente afetada pelas condições de crescimento utilizadas para sua produção e pelos procedimentos utilizados no processo pós-cultivo.

As propriedades reológicas do biopolímero devem ser estáveis durante mudanças na temperatura, $\mathrm{pH}$ e força iônica. O conhecimento sobre as propriedades dos biopolímeros, principalmente a viscosidade e o comportamento reológico são importantes para futuras aplicações industriais, refletem sua estrutura química primária e servem para predizer em quais produtos podem ser utilizados [13].

\section{4 - Análise cromatográfica}

A Figura 6 apresenta o resultado da análise cromatográfica dos biopolímeros hidrolisados em diferentes tempos de cultivo.
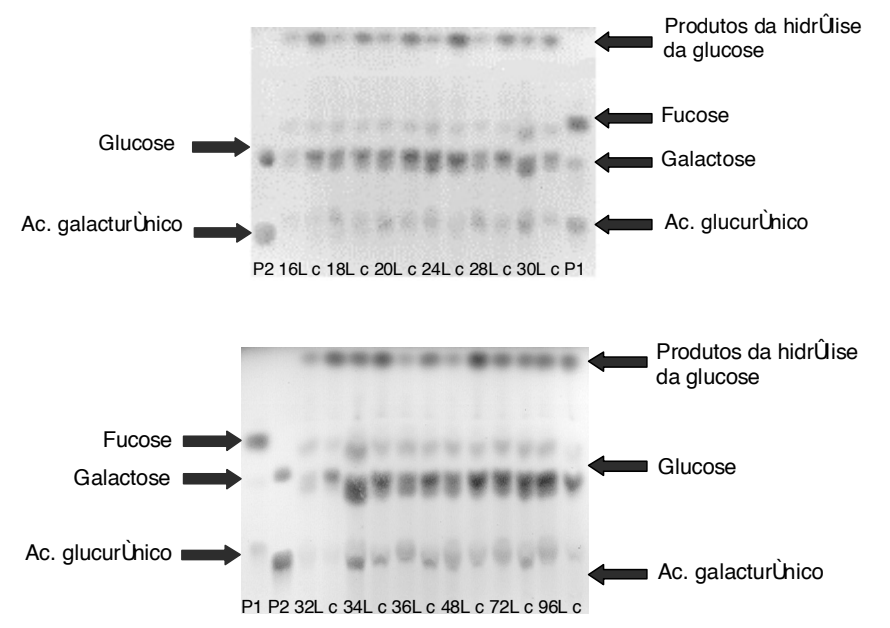

FIGURA 6. Análise cromatográfica (CCDC) das amostras de biopolímeros hidrolisados (L: fibras longas; c: fibras curtas). Padrões utilizados: fucose, galactose e ácido glucurônico (P1) e glucose e ácido galacturônico (P2).

Observou-se na Figura 6 que todos os biopolímeros apresentaram os mesmos componentes (glucose, galactose, fucose e ácido glucurônico) em concentrações diferentes. SCAMPARINI et al. [13] não detectaram o ácido glucurônico utilizando métodos espectrométricos e cromatográficos mais precisos. É possivel que este seja um produto de degradação surgido durante a hidrólise. Todos os biopolímeros de fibra curta apresentaram maior teor de glucose e os de fibra longa apresentaram, geralmente, maior teor de ácido glucurônico.

A análise de outras cepas e espécies de Beijerinckia tem revelado polissacarídeos com diferentes composições. O polímero de Beijerinckia mobilis apresentou alto conteúdo de ácido L-glucurônico [2]. O polissacarídeo CV-70 obtido por fermentação aeróbica de Beijerinckia sp contém glucose, fucose, e resíduos de galactose em uma proporção de $3: 1: 3$, todos na forma piranosídica [13]. A bactéria do solo Beijerinckia indica, que é também capaz de fixar nitrogênio, produz um polissacarídeo no qual glucose, ramnose e ácido glucurônico estão presentes em uma fração polar aproximada 6,6: 1,5:1,0. O conteúdo acetil do polímero é 9\% [6]. Para a produção do polissacarídeo em laboratório foi usado um meio contendo nitrogênio com 3\% de glicose.

Segundo MOREIRA, SOUZA \& VENDRUSCOLO [9], a semelhança estrutural existente entre os monossacarídeos dificulta a sua separação nos métodos cromotográficos clássicos, como a cromatografia em 
camada delgada comparativa. No entanto, estes métodos são os mais simples e econômicos, indicados quando o volume e freqüência de análises não justificam o emprego de métodos instrumentais complexos, como a cromatografia líquida de alta eficiência (CLAE).

Os resultados da análise cromatográfica mostraram que os biopolímeros que continham aparentemente maior teor de fucose e galactose foram também os mais viscosos.

\section{4 - CONCLUSÕES}

- As maiores produções totais de biopolímero ocorreram em 30 e 72 horas. Isso se deve, provavelmente, à maior presença de enzimas polimerizantes nestes períodos. A produção de polímeros de fibra longa aumentou com o tempo e a de fibra curta diminuiu, possivelmente pela ação de enzimas que foram polimerizando esses fragmentos. Em 30 horas ocorreu um equilíbrio entre a quantidade de fibras longas e curtas produzidas. As fibras dos polímeros de fibras longas tornaram-se ainda mais longas com o tempo.

- A maior produtividade encontrada foi após 48 horas de cultivo. A produtividade dos polímeros de fibra longa permaneceu praticamente constante e a dos de fibra curta decresceu com o passar do tempo.

- A maior viscosidade encontrada foi em 72 horas de cultivo e o polímero foi de fibra longa. Em geral, os polímeros que apresentaram maior viscosidade foram os de fibra longa, e a viscosidade dos de fibra curta permaneceu praticamente estável ao longo do tempo. A viscosidade de ambos foi igual em 30 horas de cultivo. Neste momento houve um equilíbrio na quantidade de polímeros de fibras longas e curtas. Os biopolímeros de 16 a 36 horas apresentaram comportamento newtoniano e os de 48, 72 e 96 horas, comportamento pseudoplástico.

- Todos os biopolímeros apresentaram os mesmos componentes (glucose, fucose, galactose e ácido glucurônico) em concentrações diferentes e todos os de fibra curta apresentaram maior teor de glucose. Os biopolímeros de fibra longa apresentaram, geralmente, maior teor de ácido glucurônico. Foi observado também que o teor de fucose e galactose influenciou na viscosidade.

\section{5 - REFERÊNCIAS BIBLIOGRÁFICAS}

[1] BUENO, S.M.; GARCIA-CRUZ, C.H. Influência do tempo de fermentação e presença de sais na reologia do caldo de fermentação de uma bactéria do gênero Pseudomonas isolada do solo. XVII Congresso Brasileiro de Ciência e Tecnologia de Alimentos, Fortaleza, CE, 8-10 de agosto de 2000.

[2] COOKE, A.A.; PERCIVAL, E. Structural investigation of the extracellular polysaccharides elaborated by Beijerinckia mobilis. Carbohydrate Research, v. 43, p. $117-132,1975$.
[3] COPLIN, D.L.; COOK, D. Molecular-genetics of extracellular polysaccharide biosynthesis in vascular phytopathogenic bacteria. Molecular Plant-Microbe Interactions, v. 3, p. 271-279, 1990.

[4] DONER, L.W.; DOUDS, D.D. Purification of commercial gellan to monovalent cation salts result in acute modification of solution and gel-forming properties. Carbohydrate Research, v. 273, p. 225-233, 1995.

[5] JEANES, A. Extracellular microbial polysaccharides. New hydrocolloids of interest to the food industry. Food Technology, p. 34-39, 1974.

[6] KANG, K.S.; McNEELY, W. PS-7 - A new bacterial heteropolysaccharide, L. In: SANDFORD, P. A. \& LASKIN, A. (Ed) Extracellular Microbial Polysaccharides. Washington, D.C. American Chemical Society, 1977. p. 220-230.

[7] KANG, K.S.; VEEDER, G.T. US Patent 4326053, 1982.

[8] MALDONADE, I.R. Contribuição ao estudo dos parâmetros de fermentação por Beijerinckia sp. Campinas, 1996, 79p. Dissertação (Mestrado). Faculdade de Engenharia de Alimentos, Universidade Estadual de Campinas (UNICAMP).

[9] MOREIRA, A.S.; SOUZA, A.S.; VENDRUSCOLO, C.T. Determinação da composição de biopolímero por cromatografia e camada delgada: metodologia. Agrociência, v. 3, p. 222-224, 1998.

[10] PACE, G.N. Production of extracellular microbial polysaccharides. Advances in Biochemical Engineering, v. 15, p. 41-70, 1980.

[11] PADILHA, F.F.; DELlaGOSTIN, O.A.; VENDRUSCOLO, C.T. Otimização do processo fermentativo para produção de biopolímero sintetizado por Beijerinckia sp. Ciência \& Engenharia, v. 7, n. 2, p. 49-51, 1998.

[12] RINAUDO, M. On the relation structure-propetties of some polysaccharide used in the food industry. Food Hydrocolloids, p. 510, 1993.

[13] SCAMPARINI, A.; MARIUZZO, D.; FUJIHARA, H.; JACOBUSI, R.; VENDRUSCOLO, C. Structural studies of CV-70 polysaccharide. Internacional Journal of Biological Macromolecules, v. 21, p. 115-121, 1997.

[14] SHEPHERD, R.; ROCKEY, J.; SUTHERLAND, I.W.; ROLLER, S. Novel bioemulsifiers from microorganisms for use in foods. Journal of Biotechnology, v. 40, p. 207-217, 1995.

[15] SUTHERLAND, I.W. Biosynthesis of Microbial Exopolysaccharides. Advances in Microbial Physiology. Edinburgh, 1982. Cap. 23, p. 79-106.

[16] SUTHERLAND, I.W. Microbial Biopolymers from Agricultural Products: Production and Potential. International Biodeterioration \& Biodegration, p. 249-261, 1997.

[17] SUTHERLAND, I.W. Bacterial surface polysaccharides structure and function. International Review of Cytologya Survey of Cell Biology, v. 113, p. 187-231, 1988.

[18] SYMES, K.C. Lipophylic polysaccharides. Carbohydrate Polymers, v. 2, p. 276-279, 1982.

[19] VENDRUSCOLO, C.T. Produção e caracterização do biopolímero produzido por Beijerinckia sp isolada do solo da região de Ribeirão Preto-SP Brasil, 1995, 141p. (Doutorado). Faculdade de Engenharia de Alimentos, Universidade Estadual de Campinas (UNICAMP).

[20] VENDRUSCOLO, C.T.; SCAMPARINI, A.R.P. Gellan gum - production and properties. In: NISHINARI, K.; DOI, E. (Ed) Food hydrocolloids, New York: Plenum Press, 1993. 